\title{
Survey for Highly Pathogenic Avian Influenza from Poultry in Two Northeastern States, Nigeria
}

\author{
Ibrahim Waziri Musa, Paul Ayuba Abdu, \\ Anthony Kojo Bedu Sackey, and Sunday Blessing Oladele \\ Faculty of Veterinary Medicine, Ahmadu Bello University, Zaria, Nigeria \\ Correspondence should be addressed to Ibrahim Waziri Musa; ibwazkalt@yahoo.co.uk
}

Received 4 March 2013; Revised 20 May 2013; Accepted 10 June 2013

Academic Editor: Timm C. Harder

Copyright (c) 2013 Ibrahim Waziri Musa et al. This is an open access article distributed under the Creative Commons Attribution License, which permits unrestricted use, distribution, and reproduction in any medium, provided the original work is properly cited.

\begin{abstract}
Highly pathogenic avian influenza (HPAI) is a major global zoonosis. It has a complex ecological distribution with almost unpredictable epidemiological features thus placing it topmost in the World Organization for Animal Health list A poultry diseases. Structured questionnaire survey of poultry farmer's knowledge, attitudes, and practices (KAP) in two Nigerian states revealed the presence of risk farming practices that may enable avian influenza high chance of introduction/reintroduction. There existed significant statistical association between farmer's educational levels and AI awareness and zoonotic awareness $(P<0.005)$. Poultry rearing of multiage and species (81\%), multiple sources of stock (62\%), inadequate dead-bird disposal (71\%), and access to live bird markets (LBMs) (62\%) constituted major biosecurity threats in these poultry farming communities. Haemagglutination inhibition (HI) test detected antibodies against $\mathrm{H} 5$ avian influenza (AI) in 8 of the 400 sera samples; rapid antigen detection test kit (RADTK) was negative for all the 400 cloaca and trachea swabs. These results and other poultry diseases similar to AI observed in this study could invariably affect avian influenza early detection, reporting, and control. We recommend strong policy initiatives towards poultry farmers' attitudinal change and increasing efforts on awareness of the implications of future HPAI outbreaks in Nigeria.
\end{abstract}

\section{Introduction}

Avian influenza is a highly contagious disease of primarily birds. It is worldwide known to cause devastating effects in poultry to which different strategies ranging from vaccination to stamping out, were employed to control outbreaks in recent past [1-6]. In recent times AI appears to receive most scientific investigations seeking for ways and means of AI virus containment. Notwithstanding, AI has been reemerging with increasing public health impact. In this world without borders to disease spread, no region is protected against a pandemic, and no nation remains safe when all others are at risk of AI incursion $[7,8]$. The world is now a global village in terms of international animal trade and movement hence the future wave of pandemic influenza may be difficult to predict.

Global population growth with increasing levels of poverty and food insecurity seems to initiate changing approaches in agro-livestock practices. The poultry subsector has long been recognised for its potential to significantly contribute to food security and poverty alleviation. As such, it has become so dynamic and highly intensified over the last few decades [8]. This resulted in changes in agro-livestock activities that involved difficulty in controlling trade in live birds, multiple animal species rearing, and paddy rice-fish-pigpoultry integrated farming [9-11]. These mixtures of agrolivestock practices are high-risk-based practices because they are responsible for the maintenance of AI infection. H5N1 HPAI had been reported to thrive in the presence of water bodies, bird faeces, pig populations, domestic and wild water birds, and LBMs $[7,9,11,12]$. Numerous scientific studies have reported the isolation of avian influenza viruses (AIVs) from surface water at aquatic bird habitats [11]. Live bird markets have sustained and triggered outbreaks and resurgence of HPAI in many parts of the world [11, 13, 14]. Lack of AI knowledge and unacceptable hygienic practices have also led to HPAI infections in animals other than birds [15-18]. It is 
established that H5N1 HPAI global status is dynamic, and it is also seen to be influenced by virus ecology, and various nations control intervention strategies. This has made future AI epizootics rarely predictable but postulated that next influenza pandemic may likely bear an avian origin [19-21]. This study highlighted the need to continuously evaluate poultry farmer's attitude and practices that may likely affect future early detection and action to be taken with respect to HPAI in northern Nigeria.

\section{Materials and Methods}

2.1. Study Area. The study was carried out in Bauchi and Gombe States in northeastern Nigeria in 2009 and 2011/2012. Bauchi lies between latitudes $10^{\circ} 10^{\prime}$ and $10^{\circ} 33^{\prime} \mathrm{N}$ and longitudes $9^{\circ} 40^{\prime}$ and $10^{\circ} 13^{\prime} \mathrm{E}$ in the Sudan Savannah zone [22]. Gombe state is located in the same ecological zone but lies between longitudes $10^{\circ} 45^{\prime}$ and $11^{\circ} 45^{\prime} \mathrm{N}$ and latitudes $11^{\circ} 15^{\prime}$ and $9^{\circ} 30^{\prime} \mathrm{E}$. The people are predominantly farmers. The poultry population is over two million and is made up of mainly rural poultry which are often bought and sold in live bird markets that harbour mixed species of domestic and captive birds $[22,23]$. Bauchi State had outbreaks of HPAI in 2006 and 2007 $[23,24]$. Despite the closeness and trade in live birds between the two states, Gombe State has not recorded any outbreak of HPAI $[23,25,26]$.

2.2. Sampling Technique. Cluster sampling technique was used to select three local government areas (LGA) from the three senatorial districts in each state, and five villages from selected LGA were randomly selected, making a total of 30 villages used for the study.

2.3. Epidemiological Assessment of Risk Factors to HPAI. A total of 170 structured questionnaires on HPAI risk factor assessment were administered to flock owners in various households, commercial poultry farms, and LBMs and where applicable transect walk was conducted for direct observation of poultry premises.

2.4. Serological Surveillance for HPAI. About two milliliters of blood was collected through the brachial veins from 200 each of rural and commercial poultry using a $5 \mathrm{~mL}$ syringe and a 23-gauge needle. The blood was put in a slanting position and allowed to clot at room temperature overnight. The sera were carefully decanted into $2 \mathrm{~mL}$ screw-caped serum tubes (IMEC) obtained from hospital equipment sales outlet in Kaduna, Nigeria. Haemagglutination (HA) and haemagglutination inhibition (HI) tests were conducted using the sera and standard avian influenza H5 obtained from China according to the standard laboratory protocol of OIE (2009).

2.5. Virological Surveillance for HPAI. 400 cloaca and trachea swabs were obtained from the birds and tested using Antigen Rapid H5 avian influenza detection test kits obtained from (Animal Genetics diagnostic products) Republic of Korea. The test kit is over $76 \%$ sensitive and $100 \%$ specific with a detection limit of $10^{4.9} \mathrm{EID}_{50} / \mathrm{mL}$ or $1 \mathrm{HAU}$ (http://anigene .co.kr/). The test was conducted according to the manufacturer's recommendations. All swab samples subjected to PCR detection were negative.

2.6. Statistical Analysis. Data generated from this study were analysed with Chi-square test using Statistical Package for Social Science (SPSS) version 17.5. The $P$ value of less than 0.005 was considered significant at $1 \%$ degree of freedom.

\section{Results}

3.1. Sample Collection. Table 1 summaries the areas covered, the number of birds sampled and tested during the study. We collected 400 each of tracheal and cloacal swabs and 400 serum samples from commercial and rural poultry. Of the poultry sampled, $40 \%$ were from commercial poultry farms, $40 \%$ from live-bird markets, and 20\% from backyard rural flocks (Table 2).

3.2. Rapid Antigen Detection Screening for H5 AIV. Of the 400 each of cloacal and tracheal samples subjected to analysis, 26 were from clinically sick and 374 from apparently healthy commercial and rural poultry. The samples were analysed for the presence of AI type A subtype H5 viral antigens using the rapid antigen detection test kit. Three of the clinically sick birds had clinical features and gross lesions highly suggestive of HPAI (plates 1 and 2). The clinical picture was that of rapid onset of high mortality, severe respiratory distress, cyanosis, and oedema of combs and wattles. Gross lesions observed included petechial haemorrhages in abdominal fats, thoracic cage, cecal tonsils, and proventriculus; trachea and intestines were haemorrhagic and congested. HPAI was initially suspected, and so AI and ND rapid antigen test kits (Anigen Animal Genetics Inc., Republic of Korea) were used on-farm to test for the presence of AI and ND viruses, respectively. The swabs tested positive for ND virus antigen but negative for AI. Samples (whole birds) were taken to AI regional reference laboratory (National Veterinary Research Institute, Vom, Nigeria) for further investigation. ND was further confirmed from the samples sent to the NVRI, Vom, Nigeria.

3.3. Serologic Testing. Since HPAI virus infection lasts a few days in birds and detection of AI virus antigen is best done at the onset of disease particularly during viraemia, virus could have been missed in birds that had the disease before our sampling. Therefore, we conducted serologic screening. Eight of the serum samples were positive for influenza antibodies by $\mathrm{HI}$ assay indicating an overall sero-prevalence of $2 \%$ in both states. NDV antibodies were detected in 66\% (264) of the serum samples.

3.4. Responses from Questionnaire Survey. Most farmers $(62.3 \%)$ in both states were aware of AI, but only $15.3 \%$ were aware of its zoonotic implication (Table 6). Only $9 \%$ of farmers could recognise AI disease in poultry (Table 5). The Chi-square statistical test determined significant relationship 
TABLE 1: Selected Local Government Areas, farms, birds sampled and questionnaires administered in Bauchi and Gombe States (2009/2012).

\begin{tabular}{|c|c|c|c|c|c|}
\hline State & LGA & No. of farms/households & No. of quest admin. & No. of birds sampled & No. of sera tested \\
\hline \multirow{3}{*}{ Bauchi } & Bauchi & 5 & 35 & 70 & 70 \\
\hline & Katagum & 5 & 25 & 65 & 65 \\
\hline & Ningi & 5 & 10 & 65 & 65 \\
\hline \multirow{4}{*}{ Gombe } & Funakaye & 5 & 25 & 70 & 70 \\
\hline & Kaltungo & 5 & 45 & 65 & 65 \\
\hline & Y/Deba & 5 & 30 & 65 & 65 \\
\hline & Total & 30 & 170 & 400 & 400 \\
\hline
\end{tabular}

TABle 2: Local Government Areas, farms, sera tested, sera positive for AI H5 in Bauchi and Gombe states $(n=400)$.

\begin{tabular}{lcccc}
\hline State & LGA & No. of farms/households & No. of sera tested & No. of sera positive \\
\hline \multirow{3}{*}{ Bauchi } & Bauchi & 5 & 70 & 3 \\
& Katagum & 5 & 65 & 2 \\
\multirow{3}{*}{ Gombe } & Misau & 5 & 70 & 0 \\
& Funakaye & 5 & 65 & 0 \\
\hline & Kaltungo & 5 & 65 & 2 \\
\hline
\end{tabular}

between education and $\mathrm{AI}$ awareness, and recognition and $\mathrm{AI}$ zoonotic awareness at $1 \%$ degree of freedom with a resultant $P<0.005$ (Tables 4, 5, and 6). Generally, AI awareness, recognition and zoonotic awareness in the educated group were higher than those in the noneducated groups (Tables 2, 3, and 4). However, recognition of AI was higher in the literates than the illiterates in Bauchi state, while there was no such significant difference in Gombe State.

Multiage birds had the highest responses (81\%) indicating their adoption in commercial and rural poultry farming. The multibird species keeping in rural and commercial poultry was observed in 53\% of households and commercial poultry farms. Similarly, 53\% rural households had other animal species notably dogs, pigs, goats, sheep, and cattle in close proximity to poultry. Also $62 \%$ respondents had multiple sources of birds (live bird markets, as gift from friends, and hatcheries) as breeding stocks. On the other hand, hatchery was the sole source of stock for the commercial poultry (Table 7).

Both commercial and rural poultry producers (62\%) had relationship with the LBMs in terms of live bird trading. Also, poultry housing in the rural setup was inadequate and where provided was in close proximity to human dwellings. Most commercial poultry farms were not adequately fenced as only $9 \%$ respondents had adequate fence. $5 \%$ of respondents restricted movement in and out of the commercial poultry farms (traffic control) (Table 7). Sanitary and hygienic conditions of most farms were inadequate as only $7 \%$ respondents had good hygienic measures in place (Table 8 ).

Ponds, streams and wet lands were seen in many rural areas while fish ponds were seen in some commercial poultry farms.

\section{Discussion}

Principally, risk-based veterinary surveillance is aimed at protecting the health of livestock and consumers; to some extent it also allows decision makers to prioritise and allocates resources for effective and efficient disease control strategies. Early diagnosis and rapid response are also essential and critical components for a successful control of highly infectious diseases which are likely to spread rapidly.

Knowledge, attitude, and practices (KAP) of circumstances that may lead to the introduction, persistence, and spread of HPAI using lessons from worldwide previous outbreaks must be looked into with a view to controlling future possible outbreaks [25]. The KAP analysis of the two states revealed a good level of AI awareness. However, only $9 \%$ of farmers could rightly suspect AI occurrence in poultry flocks, and $15.3 \%$ of them could appreciate the zoonotic implications of AI outbreaks especially in Bauchi state despite outbreaks of AI in 2006/2007. This appears unacceptable if an early detection and reporting system is to work well.

The overall low level of AI knowledge in the illiterate group is expected, but it means that advocacy should be intensified using local languages, jingles in the media, organising farmers' forum, and production of self-explanatory graphic pamphlets for farmers. It is worth noting that Gombe State to date had not reported AI outbreak and so the probable reason why AI knowledge appeared not to be significantly different amongst the literate and illiterate farmers.

Risk-based practices observed in this study included inadequate dead birds' disposal because $84 \%$ of farms/households either left birds to rot in the field or fed them to dogs. When birds die as a result of diseases, carcasses remain a 
TABLE 3: Literacy level and avian influenza awareness, recognition and zoonotic awareness in Bauchi and Gombe States (2009/2012).

\begin{tabular}{|c|c|c|c|c|c|c|}
\hline \multirow{2}{*}{$\begin{array}{l}\text { State } \\
\text { Bauchi }\end{array}$} & \multicolumn{2}{|c|}{$\begin{array}{c}\mathrm{AI} \\
\text { awareness } \\
\end{array}$} & \multicolumn{2}{|c|}{$\begin{array}{c}\text { AI } \\
\text { recognition }\end{array}$} & \multicolumn{2}{|c|}{$\begin{array}{c}\text { AI } \\
\text { zoonotic awareness }\end{array}$} \\
\hline & & & & & & \\
\hline Literacy level & Yes & No & Yes & No & Yes & No \\
\hline Literate & $40(57 \%)$ & $3(4.3 \%)$ & $10(14 \%)$ & $33(47 \%)$ & $15(21 \%)$ & $28(40 \%)$ \\
\hline Illiterate & $6(8.5 \%)$ & $21(30 \%)$ & 0 & $27(39 \%)$ & $3(3 \%)$ & $27(39 \%)$ \\
\hline \multicolumn{7}{|l|}{ Gombe } \\
\hline Literate & $42(42 \%)$ & $18(18 \%)$ & $15(15 \%)$ & $75(75 \%)$ & $26(26 \%)$ & $34(34 \%)$ \\
\hline Illiterate & $18(18 \%)$ & $22(22 \%)$ & $0(0 \%)$ & $100(100 \%)$ & $2(2 \%)$ & $74(74 \%)$ \\
\hline Total & 100 & 100 & 100 & 100 & 100 & 100 \\
\hline
\end{tabular}

TABLE 4: Chi square tests for literacy level and AI awareness in Bauchi and Gombe States (2009).

\begin{tabular}{lcccccccc}
\hline State & Lit. level & AI aware & $\%$ & AI not aware & $\%$ & df & $\chi^{2}$ & $P$ \\
\multirow{2}{*}{ Bauchi } & Literate & 40.0 & 57.1 & 3.0 & 21.0 & 4.3 & 1 & 36.90 \\
& Illiterate & 6.0 & 8.6 & 18.0 & 18.0 & 1 & 36.90 & 0.000 \\
\multirow{3}{*}{ Gombe } & Literate & 42.0 & 42.0 & 60.0 & 60.0 & 1 & 6.250 & 0.012 \\
& Illiterate & 18.0 & 18.0 & & 6.250 & 0.012 \\
\hline
\end{tabular}

source of infection to pen mates and other poultry on the same or other farms. It also means if carcasses are thrown into the field, dogs, cats, and other domestic animals will have access to them. Rodents are normally attracted to such environments and their activities could subsequently contaminate poultry feed and litter materials thereby assisting disease spread and posing great difficulty to disease control. Further, domestic cats have also been found to be naturally and experimentally susceptible to $\mathrm{H} 5 \mathrm{~N} 1$, and more recently, HPAI H5N1 virus has been identified as a canine pathogen [18, 27-30]. Therefore, deep burial, composting, or burning/incineration of dead or infected depopulated birds, infected poultry litter, and contaminated wastes at the infected sites should be taught to farmers as the recommended approaches to safe disposal of dead birds and infected materials $[31,32]$.

Fish ponds and untreated surface water were observed in some commercial poultry farms and few households during the course of this study. This is because poultry farmers have recently integrated fish farming to poultry. This stands the risk of attracting wild birds especially water fowls that are naturally a source of pathogenic AI. Wild birds were responsible for HPAI H5H3 outbreak in South Africa [33, 34]. Wild birds have also been reported to be infected from infected domestic poultry.

No poultry farm or household assessed in the study area had complete basic biosecurity measures in practice as indicated in Table 7. It has been documented that contaminated cages, egg flats, feed bags, and personnel played significant roles in HPAI outbreaks where inappropriate sanitary measures and movement restrictions were not imposed between and within farms and households [31]. These highrisk practices also served as major ways of virus spread to and within flocks [35]. It has been recommended that countries should regularly perform risk assessment studies of AI introduction so as to prioritise these risk factors and to find the most appropriate surveillance and control strategies to be applied $[31,36]$ as the first reported case of Asian type HPAI H5N1 in the African continent was in Nigeria, and to date the definitive route of entry into the country remains debatable [35]. Improved biosecurity and disease awareness have been reported to reduce bird mortality and further limited dissemination of AI within and between flocks [37].

Areas where multispecies and multiage flocks are kept together have assisted in frequent disease transmission and outbreaks [36-38]. Therefore, keeping multispecies, or multiage birds in the same farm premises as seen in $53 \%$ and $81 \%$, respectively, of surveyed farms in the study area is risky and dangerous practice.

Only $41 \%$ provided adequate housing for their birds so that poultry had direct contact with wild birds. It has been found out that wild birds are capable of carrying a variety of diseases causing pathogens and parasites.

We found that $62 \%$ of farmers in this study (mainly owners of rural poultry) obtained breeding stocks from and sell off their birds at LBMs. Whenever such birds were not sold at the LBMs, they were returned to farms or households together with high risk of infectious agents. Live bird markets have been tagged avenues where viruses tend to travel to and spread out into new areas that had not been previously exposed [24, 39]. In this study $62 \%$ of all farmers had access to LBMs. In depth scrutiny showed that sales of poultry at the LBMs were most common with rural poultry owners and a lower percentage of commercial poultry owners were also involved in live bird trading in LBMs. In addition live bird sellers had access to households and poultry farms especially in rural areas to purchase poultry. Some of these people may have previously handled diseased birds, thereby facilitating disease spread into poultry farms.

As part of the findings of this research, other animals like sheep, goat, cattle, and pigs and other poultry species (ducks, turkeys, geese, quails, and pigeons) were seen to be kept in close proximity to rural and commercial poultry. They could 
TABLE 5: Chi square tests for literacy level and AI recognition in Bauchi and Gombe States (2009).

\begin{tabular}{lcccccccc}
\hline State & Lit. level & AI recog. & $\%$ & AI not recog. & $\%$ & df & $\chi^{2}$ & $P$ \\
\hline \multirow{2}{*}{ Bauchi } & Literate & 10.0 & 14.3 & 33.0 & 47.1 & 1 & 7.326 & 0.005 \\
& Illiterate & 0.0 & 0.0 & 27.0 & 38.6 & 1 & 7.326 & 0.005 \\
\multirow{3}{*}{ Gombe } & Literate & 15.0 & 15.0 & 45.0 & 45.0 & 1 & 11.765 \\
& Illiterate & 0.0 & 0.0 & 40.0 & 40.0 & 1 & 11.765 & 0.001 \\
& & & &
\end{tabular}

TABLE 6: Chi square tests for literacy level and AI zoonotic awareness in Bauchi and Gombe States.

\begin{tabular}{lcccccccc}
\hline State & Lit. level & AI aware & $\%$ & AI not aware & $\%$ & $\mathrm{df}$ & $\chi^{2}$ & $P$ \\
\hline \multirow{2}{*}{ Bauchi } & Literate & 15.0 & 21.0 & 28.0 & 40.0 & 1 & 11.99 & 0.001 \\
& Illiterate & 0.0 & 0.0 & 27.0 & 38.6 & 1 & 11.99 & 0.001 \\
\multirow{3}{*}{ Gombe } & Literate & 26.0 & 26.0 & 34.0 & 34.0 & 1 & 17.49 & 0.000 \\
& Illiterate & 2.0 & 2.0 & 38.0 & 38.0 & 1 & 17.49 & 0.00 \\
\hline
\end{tabular}

TABLE 7: Levels of biosecurity practices in 170 farms in the six LGAs of Bauchi and Gombe States (2009).

\begin{tabular}{lcc}
\hline Biosecurity measures in use & Number positive & Percentage \% \\
\hline Fencing & 15 & 9 \\
Traffic control & 9 & 5 \\
Sanitation and disinfection & 12 & 7 \\
Multiage birds & 137 & 81 \\
Mixed bird species & 90 & 53 \\
Adequate housing provision & 69 & 41 \\
Multiple sources of stock & 105 & 62 \\
Other animals kept with poultry & 90 & 53 \\
Trading in LBMs & 105 & 62 \\
\hline
\end{tabular}

TABLE 8: Hygienic practices in surveyed poultry farms and households in Bauchi and Gombe States (2009/2012).

\begin{tabular}{lcc}
\hline Sanitation/disinfection & Number positive & Percentage \\
\hline Dead bird disposal & 17 & \\
Burial & 10 & 10 \\
Incineration/burning & 120 & 71 \\
Left to rot & 23 & 13 \\
Fed to dogs & 15 & 9 \\
Use of protective clothing & 69 & 41 \\
Use of disinfectants & & \\
\hline
\end{tabular}

get infected with different AI virus subtypes (especially pigs and quails) which could serve as mixing vessels to enable genetic exchange between different influenza subtypes and a consequent production of a new mutant virus with the ability for a human-to-human transmission. Genetic reassortment with viruses from different species and the emergence of drift variants in a densely human-populated area following all year-round virus circulation are common features of AI $[11,40,41]$.

\section{Conclusion and Recommendation}

Risk-based surveillance is used to strategically intervene in operational decisions especially in countries where human and financial resources are limited. Sustainable and sensitive disease surveillance system seems to depend largely on how early and accurately a disease is detected and reported. Farmers' knowledge, attitude, and hygienic practices if enhanced could assist good surveillance and enable timely confirmation of outbreaks by veterinary authorities which will prevent further spread and possible human exposure.

\section{References}

[1] M. Brudh and D. C. Johnson, "Epidemiology of avian influenza in domestic poultry," in Proceedings of the 2nd International Symposium on Avian Influenza, pp. 177-185, 1986.

[2] C. W. Beard, "Influenza and Newcastle remain a challenge," in World Poultry, pp. 9-10, 19981998.

[3] NADIS INFO, "Avian influenza," in National Animal Disease Information and Surveillance Bulletin, No. 2, p. 1, Pan African Programme for the Control Of Epizootics (PACE), Federal Department of Livestock and Pest Control Services, 2008.

[4] Office International des Epizootics (OIE), "Avian influenza," in Manual of Diagnostic Tests and Vaccines for Terrestrial Animals, Adopted Version, chapter 2.7.12, pp. 1-25, 2005.

[5] D. J. Alexander, "An overview of the epidemiology of avian influenza," Vaccine, vol. 25, no. 30, pp. 5637-5644, 2007.

[6] S. Belák, I. Kiss, and G. J. Viljoen, "New developments in the diagnosis of avian influenza," OIE Revue Scientifique et Technique, vol. 28, no. 1, pp. 233-243, 2009.

[7] C. Cardona, "Low pathogenicity avian influenza outbreaks in commercial poultry in California," in The Threat of Pandemic Influenza: Are We Ready? S. L. Knober, A. Mack, A. Mahmood, and S. M. Lemon, Eds., pp. 243-253, National Academic Press, Wishington, DC, USA, 2005.

[8] A. T. Toure, "Avian influenza," in Proceedings of the 4th International Conference on Avian Influenza, pp. 8-10, Bulletin of Animal Health and Production in Africa, Bamako, Mali, 2007.

[9] M. Artois, D. Bicout, D. Doctrinal et al., "Outbreaks of highly pathogenic avian influenza in Europe: the risks associated with wild birds," OIE Revue Scientifique et Technique, vol. 28, no. 1, pp. 69-92, 2009. 
[10] H. Chen, H. Li, Z. Li et al., "Swine influenza in China," Developmental Biology, pp. 124-173, 2006.

[11] T. van den Berg, "The role of the legal and illegal trade of live birds and avian products in the spread of avian influenza," OIE Revue Scientifique et Technique, vol. 28, no. 1, pp. 93-111, 2009.

[12] D. Kobasa, K. Wells, and Y. Kawaoka, "Amino acids responsible for the absolute sialidase activity of the influenza a virus neuraminidase: relationship to growth in the duck intestine," Journal of Virology, vol. 75, no. 23, pp. 11773-11780, 2001.

[13] J. A. Stegeman and A. Bouma, "Epidemiology and control of avian influenza," in Proceedings of the 11th International Conference of the Association of Institute for Tropical Veterinary Medicine and 16th Veterinary Association Malaysia Congress, pp. 141-143, Sunway Pyramid Convention Centre, Petaling Java, Malaysia, August 2004.

[14] W. Utterback, "Update on avian influenza through February 21, in Pensylvania and Virginia," in Proceedings of the 33rd Western Poultry Disease Conference, pp. 4-7, 1984.

[15] D. Areechokchai, C. Jiraphongsa, Y. Laosiritaworn, W. Hanshaoworakul, and M. O'Reilly, "Investigation of avian influenza (H5N1) outbreak in humans-Thailand, 2004," Morbidity and Mortality Weekly Report, vol. 55, supplement 1, pp. 3-6, 2006.

[16] B. C. Easterday, U. S. Hinshaw, and D. A. Halvorson, "Influenza," in Diseases of Poultry, B. N. Calnek, B. J. Barnes, C. N. Beard, L. R. McDougall, and Y. M. Saif, Eds., pp. 400-421, Iowa State University Press, Ames, Iowa, USA, 10th edition, 1997.

[17] M. Liu, Y. Guan, M. Peiris et al., "The quest of influenza a viruses for new hosts," Avian Diseases, vol. 47, pp. 849-856, 2003.

[18] E. Thiry, A. Zicola, D. Addie et al., "Highly pathogenic avian influenza H5N1 virus in cats and other carnivores," Veterinary Microbiology, vol. 122, no. 1-2, pp. 25-31, 2007.

[19] W. Hanson, "Avian influenza," in Field Manual of Wild Life Diseases: Birds, pp. 181-184, 2005.

[20] F. T. Jordan and M. Pattison, "Avian influenza," in Poultry Diseases, pp. 156-165, Saunders, Cambridge, UK, 4th edition, 1999.

[21] J. M. Katz, "Preparing for the next influenza pandemic," ASM News, vol. 70, no. 9, pp. 412-418, 2004.

[22] Bauchi State Agricultural Development Programme Bulletin (BSADP), pp. 5-8, 2003.

[23] "National Animal Disease Investigation and Surveillance (NADIS, 2006)," Avian Influenza Bulletin No. 2, 2006.

[24] T. Tesfai, Training the Trainer (TOT) Workshop of Live Bird Marketers and Poultry Processors Opening Remarks, 2008.

[25] A. Fusaro, T. Joannis, I. Monne et al., "Introduction into Nigeria of a distinct genotype of avian influenza virus (H5N1)," Emerging Infectious Diseases, vol. 15, no. 3, pp. 445-447, 2009.

[26] National Animal Disease Information System (NADIS), "Highly pathogenic avian influenza," in Avian Influenza Standard Operating Procedure Manual, p. 41, 2009.

[27] T. Mabbet, "H5N1 hits Africa head on-but all eyes are looking elsewhere," Poultry International, pp. 46-51, 2006.

[28] R. S. Morris and R. Jackson, "Historical background on avian influenza and emergence of the H5N1 strain," Epidemiology of H5N1 avian influenza in Asia and implications for regional control, A Contracted Report for the Food and Agricultural Organisation of the United Nations, pp. 2-4, 2005.

[29] A. W. Mounts, H. Kwong, H. S. Izurieta et al., "Case-control study of risk factors for avian influenza A (H5N1) disease, Hong Kong, 1997," Journal of Infectious Diseases, vol. 180, no. 2, pp. 505-508, 1999.
[30] G. F. Rimmelzwaan, D. van Riel, M. Baars et al., "Influenza A virus (H5N1) infection in cats causes systemic disease with potential novel routes of virus spread within and between hosts," The American Journal of Pathology, vol. 168, no. 1, pp. 176-183, 2006.

[31] Food and Agricultural Organisation (F.A.O.), "Preparing for highly pathogenic avian influenza," in Animal Production and Health Manual, no. 3, pp. 1-54, 2006.

[32] A. Nishiguchi, T. Yamamoto, T. Tsutsui et al., "Control of an outbreak of highly pathogenic avian influenza, caused by the virus sub-type H5N1, in Japan in 2004," OIE Revue Scientifique et Technique, vol. 24, no. 3, pp. 933-944, 2005.

[33] W. B. Becker, "The isolation and classification of Tern virus: influenza A-Tern South Africa-1961," Journal of Hygiene, vol. 64, no. 3, pp. 309-320, 1966.

[34] N. Promkuntod, C. Antarasena, and P. Prommuang, "Isolation of avian influenza virus A subtype $\mathrm{H} 5 \mathrm{~N} 1$ from internal contents (albumen and allantoic fluid) of Japanese quail (Coturnix coturnix japonica) eggs and oviduct during a natural outbreak," Annals of the New York Academy of Sciences, vol. 1081, pp. 171173, 2006.

[35] M. Terry, "H5N1 hits Africa head on-but all eyes are looking elsewhere," Poultry International, no. 1, pp. 5-9, 2006.

[36] X. Xu, K. Subbarao, N. J. Cox, and Y. Guo, "Genetic characterization of the pathogenic influenza A/Goose/Guangdong/1/96 (H5N1) virus: similarity of its hemagglutinin gene to those of H5N1 viruses from the 1997 outbreaks in Hong Kong," Virology, vol. 261, no. 1, pp. 15-19, 1999.

[37] S. Shane, "Avian influenza," in The Poultry Disease Handbook, pp. 13-15, American Soybean Association, 1999.

[38] E. L. Stubbs, "Fowl plague," in Diseases of Poultry, H. E. Biester and L. H. Schwarte, Eds., pp. 813-822, Iowa State University Press, Ames, Iowa, USA, 5th edition, 1965.

[39] C. E. Whiteman and A. A. Bickford, "Avian influenza," in Avian Disease Manual, pp. 1-2, The American Association of Avian Pathologist, Kennett Square, Pa, USA, 3rd edition, 1989.

[40] K. G. Nicholson, J. M. Wood, and M. Zambon, "Influenza," The Lancet, vol. 362, no. 9397, pp. 1733-1745, 2003.

[41] R. G. Webster and D. J. Hulse, "Microbial adaptation and change: avian influenza," OIE Revue Scientifique et Technique, vol. 23, no. 2, pp. 453-465, 2004. 

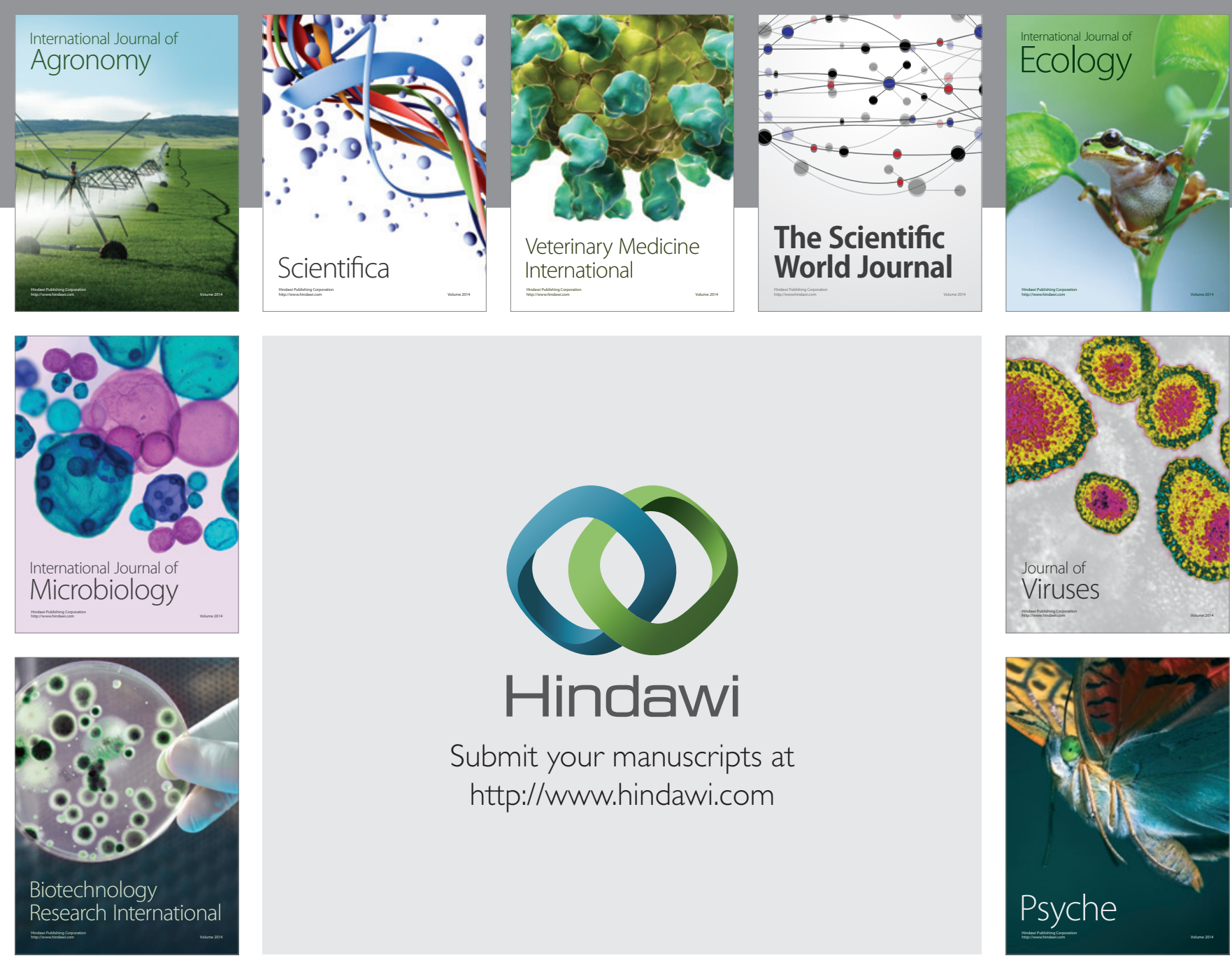

Submit your manuscripts at http://www.hindawi.com
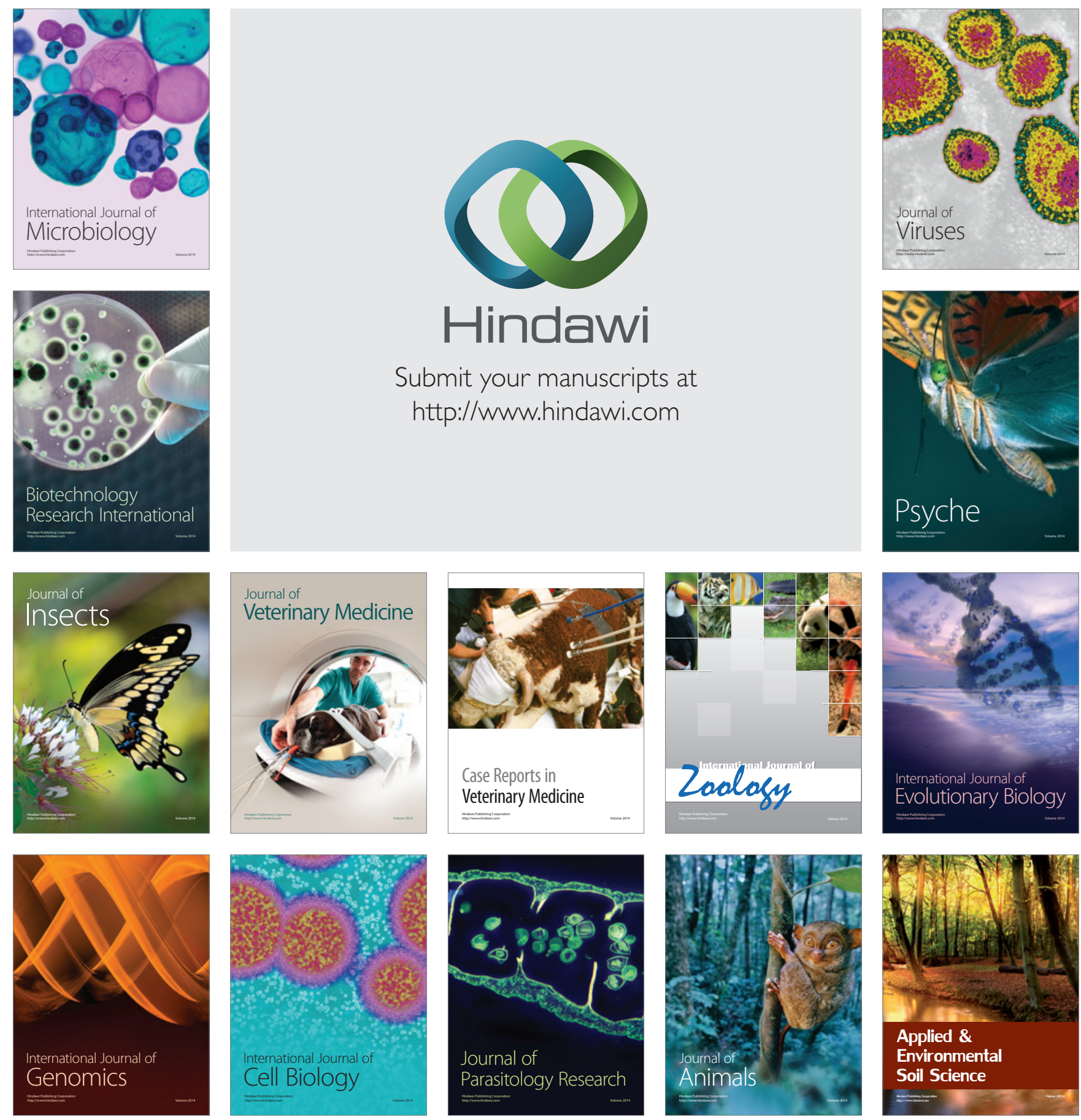